\title{
Drivers of cost differences between US breast cancer survivors with or without lymphedema
}

\author{
Lorraine T. Dean ${ }^{1,2}$ (D) $\cdot$ Yusuf Ransome ${ }^{3} \cdot$ Livia Frasso-Jaramillo $^{4} \cdot$ Shadiya L. Moss $^{5} \cdot$ Yuehan Zhang $^{6} \cdot$ Kimlin Ashing $^{7}$. \\ Gerald V. Denis $^{8} \cdot$ Kevin D. Frick ${ }^{4,9} \cdot$ Kala Visvanathan $^{1,2} \cdot$ Kathryn H. Schmitz $^{10}$
}

Received: 25 March 2019 / Accepted: 13 August 2019 / Published online: 24 August 2019

(C) The Author(s) 2019

\begin{abstract}
Purpose Breast cancer-related lymphedema is an adverse effect of breast cancer surgery affecting nearly $30 \%$ of US breast cancer survivors (BCS). Our previous analysis showed that, even 12 years after cancer treatment, out-of-pocket healthcare costs for BCS with lymphedema remained higher than for BCS without lymphedema; however, only half of the cost difference was lymphedema-related. This follow-up analysis examines what, above and beyond lymphedema, contributes to cost differences.

Methods This mixed methods study included 129 BCS who completed 12 monthly cost diaries in 2015. Using Cohen's $d$ and multivariable analysis, we compared self-reported costs across 13 cost categories by lymphedema status. We elicited quotes about specific cost categories from in-person interviews with 40 survey participants.

Results Compared with BCS without lymphedema, BCS with lymphedema faced $122 \%$ higher mean overall monthly direct costs ( $\$ 355$ vs $\$ 160$ ); had significantly higher co-pay, medication, and other out-of-pocket costs, lower lotion costs; and reported inadequate insurance coverage and higher costs that persisted over time. Lotion and medication expenditure differences were driven by BCS' socioeconomic differences in ability to pay.

Conclusions Elevated patient costs for BCS with lymphedema are for more than lymphedema itself, suggesting that financial coverage for lymphedema treatment alone may not eliminate cost disparities.

Implications for Cancer Survivors The economic challenges examined in this paper have long been a concern of BCS and advocates, with only recent attention by policy makers, researchers, and providers. BCS identified potential policy and programmatic solutions, including expanding insurance coverage and financial assistance for BCS across socioeconomic levels.
\end{abstract}

Keywords Breast cancer $\cdot$ Lymphedema $\cdot$ Financial toxicity $\cdot$ Economic burden

Lorraine T. Dean

1dean9@jhu.edu

1 Department of Epidemiology, Johns Hopkins Bloomberg School of Public Health, Johns Hopkins University, 615 N Wolfe St, E6650, Baltimore, MD 21205, USA

2 Department of Oncology, Johns Hopkins School of Medicine, Baltimore, MD, USA

3 Department of Social \& Behavioral Sciences, Yale School of Public Health, New Haven, CT, USA

4 Department of Health Policy \& Management, Johns Hopkins Bloomberg School of Public Health, Johns Hopkins University, Baltimore, MD, USA

5 Department of Epidemiology, Mailman School of Public Health, Columbia University, New York, NY, USA
6 Department of General Internal Medicine, University of Pennsylvania Perelman School of Medicine, University of Pennsylvania, Philadelphia, PA, USA

7 City of Hope Comprehensive Cancer Center, Division of Health Equities, City of Hope, Duarte, CA, USA

8 Departments of Medicine and Pharmacology, Medicine and Pharmacology, BU-BMC Cancer Center, Boston University School of Medicine, Boston, MA, USA

9 Johns Hopkins Carey Business School, Johns Hopkins University, Baltimore, MD, USA

10 Department of Public Health Sciences, Pennsylvania State University College of Medicine, Pennsylvania State University, Hershey, PA, USA 


\section{Introduction}

The economic burden of cancer treatment and its consequences, termed financial toxicity [1], remains high for breast cancer survivors (BCS) in the United States (US) [2-9]. Direct out-of-pocket costs after active treatment can range from $\$ 393$ to $\$ 561$ per month for working-aged BCS in the initial 3 years after treatment [10], and indirect costs amount to $\$ 1407$ to $\$ 2293$ per year [11]. Among low-income women, costs can be up to $98 \%$ of one's annual earnings, even with health insurance [3]. Healthcare costs are even higher for survivors who have long-term adverse effects of cancer treatments [12-18], such as breast cancer-related lymphedema [19-22]. Breast cancer-related lymphedema (BCRL) is a chronic condition that affects up to $35 \%[23,24]$ of the 3.5 million BCS in the US (2016) [25]. BCRL is an inflammatory condition that arises when there is disruption of lymphatic flow. Breast cancer surgery, adjuvant treatment, infection, or other trauma to the lymphatic system $[24,26]$ can lead to a buildup of lymphatic fluid, usually in the arms, breast, and torso [27]. The gold standard of care for lymphedema includes compression therapy (compression garments, banding) and physical therapy [28]. Greater BCRL severity is associated with low socioeconomic position [29], making affordability of BCRL care a critical concern. As a chronic condition, it may have sustained effects on finances long after treatment [30] and may even influence consumer credit [21]. Yet, costs for BCRL are largely understudied in the US context $[19,30]$.

Our previous analysis of costs for BCS in the US an average of 12 years after cancer surgery suggested significantly higher annual out-of-pocket health and wellness costs for BCS with BCRL compared with those without BCRL [30]. That study also found that only about half of the higher cost for BCS with BCRL was due to BCRL-specific needs such as specialty lotions, therapy visits, complementary and alternative therapies, compression garments and bandaging. Thus, there is a gap in understanding what, beyond BCRL-specific needs, contributes to higher costs among BCS with BCRL compared with BCS without BCRL. This follow-up analysis was conducted to detail the specific types of costs that BCS with or without BCRL face, and to understand why, beyond having BCRL, costs differ among these groups.

\section{Methods}

\section{Sample}

The current study is a follow-up study, for which details of study recruitment have been previously published [21]. From May to September of 2015, 258 women were screened by phone for eligibility in the Physical Activity and Lymphedema Social Economic and Quality of Life (PAL
SEQL) follow-up study. Recruits were identified from two sources: prior participants of the (PAL) trial $(n=295)[31$, 32] who were still alive; or participants who were ineligible $(n=163)$ for the then ongoing Women in Steady Exercise Research (WISER) Survivor Study [33-35], but met requirements for entry into PAL. All participants who had agreed to be contacted about future studies and had up-to-date contact information were contacted. Eligibility criteria included the following: women with Stages I-III invasive breast cancer after completion of active treatment; $>1$ lymph node removed, and current residents of Pennsylvania or New Jersey. Patients with active cancer or who were pregnant or planning to become pregnant in the next 6 months were excluded. Of potential participants screened, 37 were ineligible, and 96 declined or dropped out due to lack of time to commit to a longitudinal study, leaving 129 women who were enrolled in the study. Of these, 40 were selected for a qualitative interview using purposeful sampling [36] to ensure representation across BCRL status, age group (over 65 and under 65), and socioeconomic position (using education level as a proxy). After listing participant IDs for each demographic group, we randomly selected at least 10 from each group to invite to an interview; thus, a single interviewee could represent multiple demographics (e.g., over 65 and low socioeconomic position).

\section{Ethical considerations and informed consent}

The Institutional Review Board of the University of Pennsylvania approved the parent study. Written informed consent was obtained from all individual participants.

\section{Measures}

Demographics Participants self-reported current age and US census-defined race. Socioeconomic position (SEP) measures included self-reported education, total annual household income before taxes in 2014, total summed value of financial assets, and retirement status. Because financial status is a sensitive topic and subject to high non-reporting [37], income and cash assets were collected as category measures. Self-reported health insurance was classified as public (Medicaid or Medicare), private, or none with some participants reporting both public and private insurance, which were counted in both categories.

Direct out-of-pocket costs and indirect costs over 12 months (cost diary) The data collection instrument developed was based on the Goossens' cost diary, a validated tool for collecting out-of-pocket cost data [38]. Details on this method are documented elsewhere [20] and summarized in the "data collection" section. Direct costs included co-payments for outpatient physician office visits, physical and occupational 
therapy visits, complementary and integrative therapy visits, emergency department visits, hospitalizations, labs, x-rays and tests; wellness resources (e.g., gym memberships); BCRL-specific healthcare needs (compression garments, bandages); medications or other health-related product that a participant identified; and health insurance premiums if paid outof-pocket. Other out-of-pocket costs included payments for pain relief medicine, transportation, and nutritional and vitamin supplements. We used an opportunity cost approach [39] to assess indirect costs for lost work or activity hours, and lost assets due to payments for caregiving. Indirect costs were assessed with two questions on (a) number of days which they were unable to perform usual activities; and (b) number of hours of help they needed to carry out daily activities. Participants with BCRL received a version of each question that specified whether the additional help was needed "due to lymphedema". Patients who reported needing help around the house also reported the number of hours they had paid for domestic assistance. To calculate a monetary equivalent for opportunity costs of lost work, the adjusted mean number of missed workdays was multiplied by the median hourly wage (\$16.87) for a 6-h workday based on the US Bureau of Labor Statistics [40] estimates and recommendations for calculating work losses. To calculate the monetary equivalent for domestic assistance, the mean number of hours was multiplied by the daily household productivity rate (\$43.37) [41] adjusted to the Consumer Price Index [42].

Cancer history and treatments Participants self-reported completion of chemotherapy and/or radiation therapy and/or hormone therapy after cancer surgery, year of breast cancer diagnosis, and cancer stage at diagnosis. Self-report of breast cancer treatment has been validated as over $90 \%$ congruent with medical records [43]. We modeled the total number of types of treatments, which is more important to cost than the details of treatment.

Health conditions and lymphedema Participants self-reported any of 23 comorbidities and previous diagnosis of breast cancer-related lymphedema (BCRL). To measure upper body BCRL severity, inter-limb volume difference measurements between the affected and unaffected arms were taken using perometry (Juzo, Germany) and were adjusted for humidity, barometric pressure, and time of day. Women who wore compression garments were asked to remove them for at least $1 \mathrm{~h}$ prior to perometry assessment.

\section{Data collection}

The same set of data collection procedures were used in this follow-up study as in the parent study [21,30]. At baseline, participants completed a demographic and health history survey, including report of previous BCRL diagnosis by a health professional, followed by monthly cost diaries. At the start of the study period, participants reported direct and indirect (opportunity) costs related to their overall healthcare [44] for the past 3 months. Then, for each of the next 6 months, participants prospectively reported costs. For the final 3 months, participants estimated projected costs to capture any annual or scheduled visits. This procedure yielded a total of 12 months of cost data. Participants who did not complete a cost diary in a particular month were not included in that month's analysis and offered no contributing data to that month's cost estimates. At the end of the 12-month period (November 2015 to January 2016), a subset of survey respondents participated in qualitative interviews, constituting an explanatory sequential design $[45,46]$. This approach entails first collecting quantitative data and then collecting qualitative data to inform and provide context for quantitative findings. The standardized semi-structured interview guide (see Appendix of [30]), developed by the study principal investigator (PI), included questions on economic challenges, supports utilized, patient perception of the most challenging economic event since their cancer diagnosis, lasting impact of economic burden, and resource gaps after participants' breast cancer diagnosis. The study PI (LTD) and a trained research assistant (SLM) conducted interviews. Interviews lasted approximately 15 to $30 \mathrm{~min}$ and were conducted in private rooms. Transcripts were de-identified and transcribed verbatim. Quantitative survey data and qualitative interview data were linked through participant study IDs.

\section{Data analysis}

Quantitative component Demographic characteristics were compared for participants with BCRL versus without BCRL using Chi-squared test with Fischer's statistic for demographic categories with less than 5 respondents, and non-parametric rank sum tests for non-normally continuously distributed variables. In contrast with the parent study [30], this follow-up analysis focused on how and why costs differed by BCRL status for specific cost categories. Thus, the current study reports unadjusted cost estimates and differences due to smaller sample sizes within the cost categories. Monthly costs by category were compared using Cohen's $d$ and bootstrapped estimates with 200 replications with a seed of (111), allowing us to obtain confidence intervals for non-normally distributed data.

Since our previous analysis estimated that only half of cost differences were due to BCRL costs, the next step of the current analysis sought to understand what drove cost differences between BCS with and without BCRL. We explored this in two steps, focusing only on cost categories that were significantly different by BCRL status. For each category, we generated two models using generalized estimating equations 
(GEE) with negative binomial distributions. Model 1 used BCRL as an exposure and adjusted for income because it was the only sociodemographic variable that was significantly different by BCRL status. If Model 1 showed BCRL to be significantly related to costs for that category, a second model was generated further adjusting for socioeconomic clinical characteristics. Model 2 gave insight on which variables, above and beyond BCRL status, could potentially account for cost differences. Our previous work suggested that, after adjusting for years since cancer diagnosis, race and age would not be significant predictors in this sample [29] and thus were not included in the multivariable models.

Qualitative analysis Verbatim interview transcripts were input into MAXQDA software program for qualitative analysis. The same qualitative methods and codebook were used for this follow-up study and its previous parent study [30]. First, structural codes were identified based on the domains of economic burden after cancer [44]; then, we added codes based on what emerged from the interviews. The research team organized these codes into a codebook, with subcodes for explanations of specific cost categories. The same text segment could have multiple codes. Each fifth transcript was coded by two analysts. Discrepancies were discussed and resolved among the research team. We then divided the transcripts into groups by BCRL status and compared quotes related to each cost category for each group. Representative quotes are reported to illustrate key findings.

\section{Results}

The 129 participants who contributed data to the quantitative analysis are described in Table 1. The mean age was 63 and the average time since cancer diagnosis was 12 years. Just under half $(46.5 \%)$ of the participants were diagnosed with BCRL. There was no statistically significant difference by BCRL status in mean age, race, education, wealth, retirement status, and type of insurance. A significantly greater percentage of BCRL were in a lower income category $(p=0.02)$ compared with those without BCRL. Cancer stage at diagnosis, type of adjuvant treatments, and number of comorbidities did not differ by BCRL status. Those with BCRL were on average 3 years farther out from diagnosis $(p=0.002)$ and had greater inter-limb difference $(p<0.001)$. Of the 40 participants who completed qualitative interviews, $24(60 \%)$ had BCRL; the interviewee subset had a greater proportion of high school-educated participants than the overarching quantitative study participant pool.

As shown in Table 2, participants with BCRL faced 122\% higher average monthly direct costs $(d=-0.16,95 \%$ CI [$0.25,-0.07]$ ). Despite an equal number of average monthly medical visits, costs were statistically higher for women with
BCRL for the categories of co-pays $(131 \% ; d=-0.15,95 \%$ CI $[-0.24,-0.05])$, medications $(46 \% ; d=-0.17,95 \% \mathrm{CI}$ $[-0.29,-0.04])$, and other out-of-pocket costs $(167 \% ; d=-$ $0.09,95 \%$ CI $[-0.18,-0.01])$; but lower for lotions $(-28 \%$; $d=0.29,95 \%$ CI $[0.01,0.57])$. No other variables were statistically different by BCRL status based on effect size difference calculations.

Table 3 includes the results for the cost categories from Table 2 that were significantly different by BCRL status. For co-pays, above and beyond BCRL, patients at the middleincome tier experienced greater costs $(\mathrm{PR}=1.02,95 \% \mathrm{CI}$ $[1.01,1.04])$ than those in the lowest income levels. For lotions and medications, BCRL did not explain cost differences, but was largely driven by those with highest incomes spending more on lotions (PR $=2.05,95 \% \mathrm{CI}[1.20,3.50])$ and medications ( $\mathrm{PR}=1.01,95 \% \mathrm{CI}[1.00,1.02])$. For other outof-pocket costs, having BCRL primarily explained cost differences $(\mathrm{PR}=1.01,95 \% \mathrm{CI}[1.00,1.02])$.

\section{Qualitative findings}

Table 4 includes quotes from the qualitative interviews that help further explain why selected costs differed by BCRL status. Not all costs were mentioned in qualitative analysis; thus, quotes are given only for those categories that were brought up by participants during qualitative interviews. Key differences that emerged when comparing those with BCRL with those without BCRL included timing of cancer-related costs, adequacy of insurance coverage, and the role of patients' socioeconomic position in the use or purchase of health needs.

\section{Theme 1: Ongoing costs persist for BCS, but are different by BCRL status}

Women with BCRL reported ongoing costs that continued in the long-term, especially for co-pays and compression garments. For example, respondents with BCRL recounted how co-pay prices have increased over time and referred to comparative past and present experiences, while those without BCRL were more likely to discuss the impact of co-pay prices closer to the time of treatment. Additionally, for women with BCRL, other ongoing out-of-pocket direct costs included transportation to ongoing BCRL therapy or purchase of additional health-related foods and supplements to improve overall health and manage BCRL symptoms. Because BCRL is a chronic condition, these costs would be ongoing and lifelong. Women with and without BCRL both suggested that medication costs were an ongoing challenge that compromised their ability to take multi-year oral anti-cancer adjuvant treatments. 
Table 1 Participant baseline characteristics

\begin{tabular}{|c|c|c|c|c|}
\hline$N=129$ & $\begin{array}{l}\text { BCRL* Yes } \\
n=60(46.51 \%)\end{array}$ & $\begin{array}{l}\text { BCRL* No } \\
n=69(54.49 \%)\end{array}$ & $p$ value & $\begin{array}{l}\text { Interviewees } \\
N=40\end{array}$ \\
\hline \multicolumn{5}{|l|}{ Demographics } \\
\hline Age in years, $M(S D)$ & $65(8)$ & $62(8)$ & 0.11 & $64(8)$ \\
\hline Race & & & 0.32 & \\
\hline White & $35(57.4)$ & $41(60.3)$ & & $21(52.5)$ \\
\hline Black & $24(39.3)$ & $26(38.2)$ & & $17(42.5)$ \\
\hline Other & $2(3.3)$ & $0(0.0)$ & & $2(5)$ \\
\hline Education completed & & & 0.35 & \\
\hline High school & $17(27.9)$ & $13(19.1)$ & & $19(47.5)$ \\
\hline College & $26(42.6)$ & $29(42.7)$ & & $12(30)$ \\
\hline Graduate school & $17(27.9)$ & $26(38.2)$ & & $9(22.5)$ \\
\hline Income & & & 0.02 & \\
\hline$\leq \$ 30,000$ & $8(13.1)$ & $11(16.2)$ & & $4(10.5)$ \\
\hline$\$ 30,001-\$ 70,000$ & $30(49.2)$ & $18(26.5)$ & & $22(57.8)$ \\
\hline$>\$ 70,000$ & $19(31.2)$ & $35(51.5)$ & & $12(31.6)$ \\
\hline Total cash assets & & & 0.60 & \\
\hline$\leq \$ 4,999$ & $17(27.9)$ & $16(23.5)$ & & $12(35.1)$ \\
\hline$\$ 5,000-\$ 49,999$ & $16(26.2)$ & $13(19.1)$ & & $10(27.0)$ \\
\hline$\$ 50,000-\$ 499,999$ & $13(21.3)$ & $19(27.9)$ & & $10(27.0)$ \\
\hline$\geq 500,000$ & $9(14.8)$ & $13(19.1)$ & & $4(10.8)$ \\
\hline Retired & $22(36.1)$ & $15(22.1)$ & & $10(25.0)$ \\
\hline Insurance type & & & 0.08 & \\
\hline Public & $21(34.4)$ & $19(27.9)$ & 0.43 & $12(30)$ \\
\hline Private & $49(80.3)$ & $53(77.9)$ & 0.74 & $33(82.5)$ \\
\hline None & $1(1.6)$ & $2(2.9)$ & 0.62 & 0 \\
\hline \multicolumn{5}{|l|}{$\begin{array}{l}\text { Cancer diagnosis and treatment } \\
\text { variables }\end{array}$} \\
\hline Cancer stage at diagnosis & & & 0.09 & \\
\hline Stage 0 & $9(14.8)$ & $10(14.7)$ & & $10(32.3)$ \\
\hline Stage 1 & $11(18.0)$ & $22(32.4)$ & & $9(29.0)$ \\
\hline Stage 2 & $11(31.2)$ & $19(16.2)$ & & $7(22.6)$ \\
\hline Stage 3 & $9(14.8)$ & $6(8.8)$ & & $5(16.1)$ \\
\hline Missing & $13(21.3)$ & $19(27.9)$ & & $9(22.5)$ \\
\hline Years since cancer diagnosis (SD) & $13(6)$ & $10(3)$ & 0.002 & $12(5)$ \\
\hline $\begin{array}{l}\text { Number of adjuvant treatment } \\
\text { modalities (SD) }\end{array}$ & $2(1)$ & $2(1)$ & 0.13 & \\
\hline Radiation & $51(83.6)$ & $53(77.9)$ & 0.42 & $33(82.5)$ \\
\hline Chemotherapy & $51(83.6)$ & $46(67.7)$ & 0.05 & $30(76.9)$ \\
\hline Hormonal therapy & $29(47.5)$ & $34(50)$ & 0.79 & $10(25)$ \\
\hline Comorbidities & $1(1)$ & $1(1)$ & 0.46 & $2(1)$ \\
\hline Inter-limb difference $(\%)$ & $9.3(13.4)$ & $-0.8(6.1)$ & $<0.001$ & $7.7(15.0)$ \\
\hline
\end{tabular}

* BCRL breast cancer-related lymphedema

\section{Theme 2: Inadequacy of insurance}

Both women with and without BCRL spoke on the inadequacy or high cost of insurance coverage that precluded getting care for BCRL or other comorbid conditions. Patients with BCRL reported BCRL-specific treatments or supplies that may not have been comprehensively covered by existing insurance plans. For example, insurance did not typically cover compression garments, bandages, or sleeves, resulting in several hundred dollars in out-of-pocket costs. One respondent without BCRL described how switching to public insurance that had a more limited formulary complicated her ability to take medications for comorbid conditions. She further described how costs for medications could change due to an 
Table 2 Monthly cost comparisons for breast cancer survivors with lymphedema or without lymphedema

\begin{tabular}{|c|c|c|c|c|}
\hline \multirow[b]{2}{*}{ Cost category } & \multicolumn{3}{|l|}{ Average expenses } & \multirow[b]{2}{*}{$\begin{array}{l}\text { Cohen's } d \text {, } \\
95 \% \text { confidence interva }\end{array}$} \\
\hline & BCRL* Yes & BCRL* No & $\%$ difference & \\
\hline Number of health provider visits & $1.54(1.9)$ & $1.50(2.69)$ & $4 \%$ & $-0.01,(-0.14,0.11)$ \\
\hline Total direct costs & $\$ 355.0(\$ 1676.8)$ & $\$ 159.6(\$ 373.6)$ & $122 \%$ & $-0.16,(-0.25,-0.07)$ \\
\hline Office visit co-pays & $\$ 94.2(\$ 481.8)$ & $\$ 41.0(\$ 167.3)$ & $131 \%$ & $-0.15,(-0.24,-0.05)$ \\
\hline Alternative treatments & $\$ 16.5(\$ 84.7)$ & $\$ 10.7(\$ 45.7)$ & $54 \%$ & $-0.08,(-0.21,0.04)$ \\
\hline Labs and X-rays & $\$ 12.3(\$ 92.2)$ & $\$ 7.3(\$ 72.4)$ & $68 \%$ & $-0.06,(-0.18,0.06)$ \\
\hline Compression garments/bandaging & $\$ 350(\$ 459.3)$ & N/A & N/A & N/A \\
\hline Lotions & $\$ 20.7(\$ 23.1)$ & $\$ 28.8(\$ 30.0)$ & $-28 \%$ & $0.29,(0.01,0.57)$ \\
\hline Gym memberships & $\$ 38.9(\$ 35.9)$ & $\$ 35.8(\$ 30.0)$ & $9 \%$ & $-0.08,(-0.32,0.15)$ \\
\hline Medications & $\$ 60.1(\$ 149.5)$ & $\$ 41.1(\$ 56.8)$ & $46 \%$ & $-0.17,(-0.29,-0.04)$ \\
\hline Emergency room (in-patient) costs & $\$ 18.7(\$ 37.2)$ & $\$ 15.0(\$ 47.4)$ & $25 \%$ & $-0.14,(-1.41,1.12)$ \\
\hline Out-patient hospital costs & $\$ 14.6(\$ 38.5)$ & $\$ 4.0(\$ 12.6)$ & $290 \%$ & $-0.48,(-1.72,0.76)$ \\
\hline Other out-of-pocket costs & $\$ 157.6(\$ 1456.6)$ & $\$ 59.1(\$ 288.0)$ & $167 \%$ & $-0.09,(-0.18,-0.01)$ \\
\hline Cost for hired help & $\$ 106.5(\$ 115.7)$ & $\$ 103.3(\$ 104.0)$ & $3 \%$ & $-0.03,(-0.51,0.45)$ \\
\hline Number of hours for hired help & $2.77(13.3)$ & $3.10(12.69)$ & $-13 \%$ & $0.06,(-0.36,0.48)$ \\
\hline Opportunity costs, work & $\$ 124.9(\$ 666.5)$ & $\$ 191.7(\$ 747.3)$ & $-35 \%$ & $0.10,(-0.05,0.25)$ \\
\hline Opportunity costs, home & $\$ 9.6(\$ 45.0)$ & $\$ 7.1(\$ 36.3)$ & $35 \%$ & $-0.06,(-0.22,0.11)$ \\
\hline
\end{tabular}

Cohen's $d$ computed for effect size in the difference in means using bootstrapped estimates with 200 replications and seed (111) to obtain $95 \%$ confidence interval. Effect sizes are significant if the confidence interval does not contain zero.

$N / A$ no observations in other category for a comparison

* BCRL breast cancer-related lymphedema

insurance "donut hole", referring to a point when, after having an initial amount of services covered, publicly insured (i.e.., Medicare Part D) patients pay full price for medications until their out-of-pocket maximum is met and insurance coverage resumes. Cost for supplemental insurance contributed to higher out-of-pocket direct costs for BCS in both groups.

\section{Theme 3: Socioeconomic position helps and hinders access to post-cancer healthcare}

BCS' socioeconomic position amplified challenges with accessing health care for post-cancer care and BCRL, especially in the categories of medication and other out-of-pocket costs. One respondent without BCRL described having to stop work due to her cancer diagnosis and the resultant loss of income due to lost work made it challenging to afford medications. BCS with BCRL had to concurrently navigate costs for BCRL therapy on top of adjuvant treatments. As a result, BCS with BCRL had to trade off financial reserves initially intended to secure a future of financial stability, such as retirement funds, or to forgo taking medication as prescribed. For out-of-pocket costs, socioeconomic position emerged again as critical to understanding the patient's experience. Another quote exemplified that patients at higher income levels still faced challenges with affording care, yet were often ineligible for assistance with their needs.

\section{Discussion}

This study is one of the few to examine the economic burden of breast cancer-related lymphedema, a chronic adverse effect of breast cancer surgery, and to explore specifically what contributes to higher costs for BCRL patients, above and beyond BCRL itself. Monthly average costs for breast cancer survivors (BCS) who have BCRL were $122 \%$ higher than BCS who do not have BCRL. Five types of costs vary significantly by BCRL status, and BCRL patients reported that higher costs persisted in the long-term: co-pays, lotions, compression garments, medications, and out-of-pocket costs. Study results reinforce previous findings that patients with BCRL continue to face higher costs, in some part, due to BCRL. This analysis extends this finding to show that divergent costs are exacerbated by underlying pre-morbid socioeconomic and insurance challenges.

Our results point to a need to mitigate healthcare costs, including co-pays, medications, and other health needs that may be paid out-of-pocket by BCS across resource levels, especially for BCS with BCRL. Having BCRL was a contributor to higher costs for co-pays and items listed under other out-of-pocket costs. BCS with BCRL paid over double in copay costs despite having the same average number of medical visits compared with non-BCRL BCS. This disparity may suggest that BCS with BCRL have higher cost insurance 
Table 3 Prevalence ratios and 95\% confidence intervals for drivers of cost differences, above and beyond lymphedema

\begin{tabular}{|c|c|c|c|c|c|c|}
\hline & \multicolumn{2}{|l|}{ Co-pays } & \multirow{2}{*}{$\begin{array}{l}\text { Lotions } \\
\text { Model } 1 \\
N=168\end{array}$} & \multirow{2}{*}{$\begin{array}{l}\text { Medications } \\
\text { Model } 1 \\
N=456\end{array}$} & \multicolumn{2}{|c|}{ Other out-of-pocket costs } \\
\hline & $\begin{array}{l}\text { Model } 1 \\
N=905\end{array}$ & $\begin{array}{l}\text { Model } 2 \\
N=722\end{array}$ & & & $\begin{array}{l}\text { Model } 1 \\
N=905\end{array}$ & $\begin{array}{l}\text { Model } 2 \\
N=722\end{array}$ \\
\hline Lymphedema & $\begin{array}{l}1.01 \\
(1.00,1.02)\end{array}$ & $\begin{array}{l}1.00 \\
(0.99,1.01)\end{array}$ & $\begin{array}{l}0.77 \\
(0.48,1.21)\end{array}$ & $\begin{array}{l}1.01 \\
(0.99,1.02)\end{array}$ & $\begin{array}{l}1.01 \\
(1.00,1.02)\end{array}$ & $\begin{array}{l}1.00 \\
(0.99,1.01)\end{array}$ \\
\hline \multicolumn{7}{|l|}{ Income $(\mathrm{ref}=\leq \$ 30,000)$} \\
\hline$\$ 30,001-\$ 70,000$ & $\begin{array}{l}1.01 \\
(1.00,1.04)\end{array}$ & $\begin{array}{l}1.02 \\
(1.01,1.04)\end{array}$ & $\begin{array}{l}1.67 \\
(0.97,2.87) \text {, }\end{array}$ & $\begin{array}{l}1.00 \\
(0.99,1.01)\end{array}$ & $\begin{array}{l}1.00 \\
(0.98,1.02)\end{array}$ & $\begin{array}{l}0.99 \\
(0.98,1.01)\end{array}$ \\
\hline$>\$ 70,000$ & $\begin{array}{l}1.01 \\
(0.99,1.03)\end{array}$ & $\begin{array}{l}1.00 \\
(1.00,1.00)\end{array}$ & $\begin{array}{l}2.05 \\
(1.20,3.50)\end{array}$ & $\begin{array}{l}1.01 \\
(1.00,1.02)\end{array}$ & $\begin{array}{l}1.01 \\
(0.99,1.03)\end{array}$ & $\begin{array}{l}1.00 \\
(0.99,1.02)\end{array}$ \\
\hline Years since cancer diagnosis & & $\begin{array}{l}0.99 \\
(0.99,1.00)\end{array}$ & & & & $\begin{array}{l}1.00 \\
(1.00,1.00)\end{array}$ \\
\hline \multicolumn{7}{|c|}{ Number of adjuvant treatments $(\mathrm{ref}=4)$} \\
\hline 1 & & $\begin{array}{l}0.99 \\
(0.97,1.03)\end{array}$ & & & & $\begin{array}{l}1.04 \\
\left(\begin{array}{l}0.96 \\
1.13\end{array}\right)\end{array}$ \\
\hline 2 & & $\begin{array}{l}1.00 \\
(0.98,1.03)\end{array}$ & & & & $\begin{array}{l}1.05 \\
(0.97,1.14)\end{array}$ \\
\hline 3 & & $\begin{array}{l}1.01 \\
(0.99,1.03)\end{array}$ & & & & $\begin{array}{l}1.05 \\
(0.97,1.14)\end{array}$ \\
\hline Number of comorbidities & & $\begin{array}{l}1.00 \\
(1.00,1.01)\end{array}$ & & & & $\begin{array}{l}1.00 \\
(1.00,1.00)\end{array}$ \\
\hline \multicolumn{7}{|c|}{ Cancer stage at diagnosis $($ ref $=$ Stage 0$)$} \\
\hline Stage 1 & & $\begin{array}{l}1.00 \\
(0.99,1.01)\end{array}$ & & & & $\begin{array}{l}1.01 \\
(0.98,1.03)\end{array}$ \\
\hline Stage 2 & & $\begin{array}{l}1.01 \\
(0.99,1.01)\end{array}$ & & & & $\begin{array}{l}1.01 \\
(0.99,1.03)\end{array}$ \\
\hline Stage 3 & & $\begin{array}{l}1.00 \\
(0.98,1.01)\end{array}$ & & & & $\begin{array}{l}1.00 \\
(0.97,1.02)\end{array}$ \\
\hline
\end{tabular}

Based on GEE analysis with independent correlation matrix and robust, adjusted standard error estimates for clustering. Italicized values indicate factors that were significant contributors to cost differences. The $N$ for each analysis is the total observations over the eight periods in the multivariable analysis. Some of the significant and non-significant point estimates and confidence intervals appear the same due to rounding up to the nearest two significant digits

plans, though this would need to be explicitly explored in further research. Lower expenditures on lotions and higher payments for medications were better explained by underlying differences in socioeconomic position than BCRL status. While high socioeconomic position patterned greater access to lotions and medications, interviewees suggested that high socioeconomic position did not fully protect against economic challenges and that women who do not quality for assistance may still need help. For both BCS with and without BCRL, patients reported a need to make trade-offs between healthcare spending and doing what was best for their health. Patients with limited financial resources had to choose between adherence to medically necessary treatments and managing other health and living needs, often resorting to creative ways to access medications. Taken together, we interpret these results to mean that intervening on BCRL costs alone may not be sufficient to mitigate cost differences or overall cost burden and that patients across the socioeconomic spectrum may need relief from economic challenges. Given the ongoing nature of economic challenges, relief may need to be extended well beyond the initial post-treatment stages.

High medical non-cancer costs of nearly $\$ 15,000$ for the first 2 years of BCRL treatment for working-aged BCS has been previously documented [19], with most of the costs attributed to outpatient visits unrelated to cancer treatment, probable complications of BCRL, or physical therapy. Medications and BCRL management supplies also contributed to higher costs [19] for BCS with BCRL. The present study's results emphasize that high costs persist even an average of 12 years later and that costs are overall more than double for participants with BCRL. Patients with BCRL discussed the challenges of managing a chronic condition that has ongoing costs. In particular, patients with BCRL described ongoing co-pay costs that recurred over time while patients without BCRL described co-pay costs as being concentrated around time of treatment. Our findings suggest that a BCS' path to manage their health over time may be set early on in the survivorship period (i.e., cancer treatment recovery phase) 


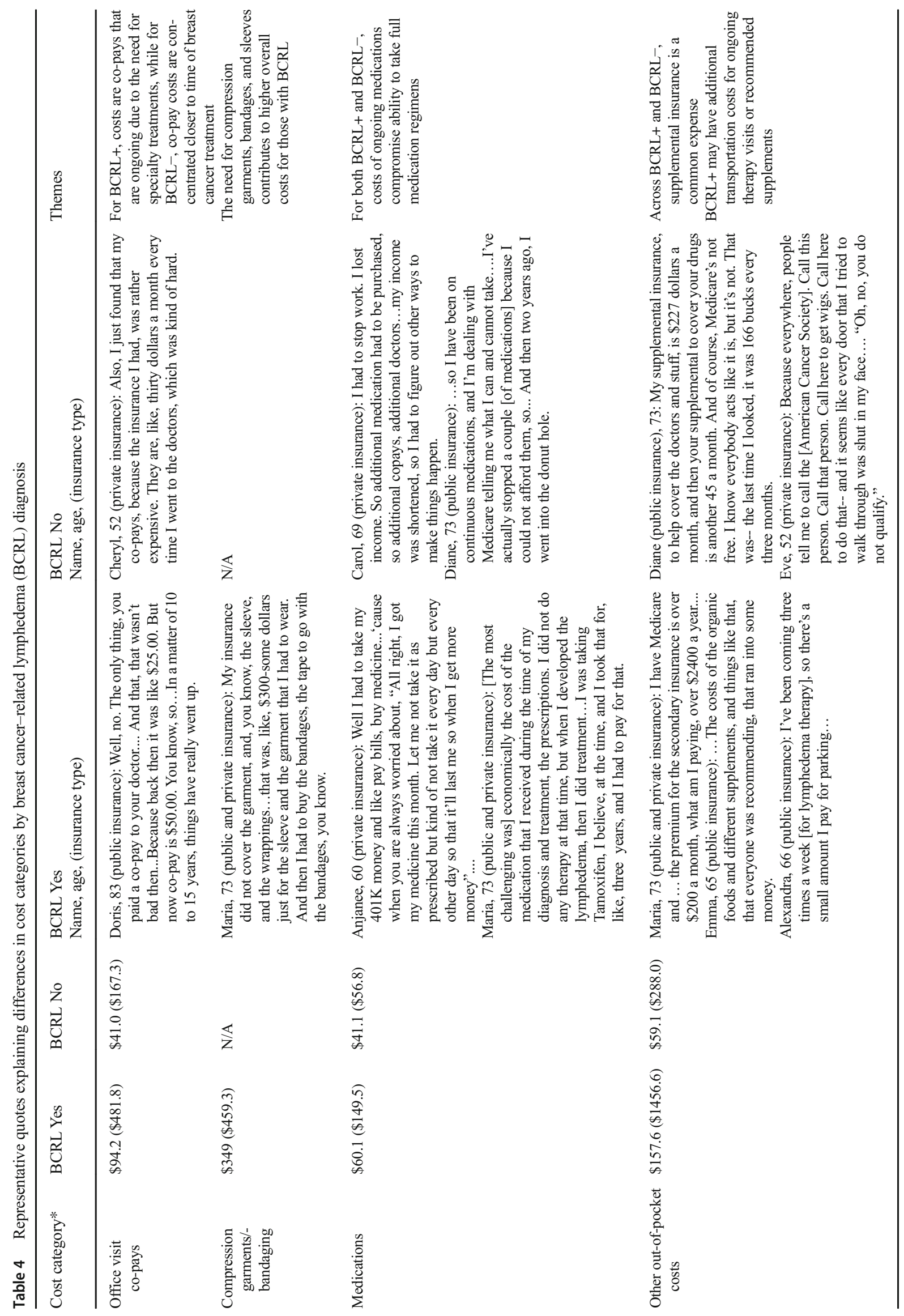


and is influenced by their pre-morbid socioeconomic condition.

While monthly out-of-pocket direct cost estimates found in our study are less than the previously estimated $\$ 393$ to $\$ 561$ for working-aged BCS [10], previous estimates are based on a time close to cancer diagnosis and treatment, when patients may still have been using adjuvant treatments. In contrast, our study estimates costs for long-term BCS. This difference suggests that, while still elevated, costs may lessen over time. Nonetheless, our results suggest that even at a monthly cost of $\$ 160$ for BCS without BCRL and \$355 for BCS without BCRL, the cascading of costs [30] accumulates over time and may pose strain.

\section{Research and policy implications}

Previous studies have suggested ways to reduce costs for BCS [44, 47-50], including reducing direct medical costs; increasing the affordability and comprehensiveness of insurance coverage; giving patients prompt information on costs and access to social workers, navigators, and support groups knowledgeable about resources to reduce economic burden; expansion of financial aid, employment protective policies, and home healthcare services. While these recommendations are not specific to BCRL, our results suggest that women with BCRL have higher healthcare costs and needs that may not be directly related to BCRL, and thus, reducing both overall and BCRL-specific healthcare costs can help. Offering assistance for medications, in addition to other healthcare needs like transportation and nutritional supplements, may help socioeconomically vulnerable patients better afford care to manage BCRL and other comorbidities. Given the cascading nature of costs for BCS, early financial intervention for patients who are at risk for chronic decline or managing chronic adverse effects could reduce long-term care costs and morbidity. To determine who early financial interventions should target, future studies should develop risk profiles based on social, economic, and biological risk factors to identify who would most benefit from early financial intervention.

Inadequate insurance coverage for BCRL-related care emerged as a challenge for patients with BCRL and without BCRL. Costs for compression garments and bandages were present only for BCS with BCRL, which contribute to higher overall costs per month since, as the qualitative interviews report, they are not always covered by insurance. High costs will cause patients to use compression garments that no longer apply sufficient pressure to manage BCRL $[22,30]$. In the current study and prior, patients recommend insurance providers expand coverage to include BCRL self-management care, including compression garments and bandages [50]. Policymakers can impact coverage as well. A 2016 report found that expanding insurance coverage to include comprehensive BCRL treatment in one state had a less than $0.1 \%$ impact on the cost of insurance claims. Coverage included products for self-management, which nearly halved the number of office visits patients needed for BCRL treatment, thus reducing patient office visit costs [51]. The Lymphedema Treatment Act, an amendment to Title XVIII of the Social Security Act (Medicare) to cover certain lymphedema compression treatment items as durable medical equipment, has been introduced to Congress several times [52]. Insurance design plans that encourage equity in costs across individual insurance plans, such as value-based designs, could help mitigate cost disparities across BCS [53].

\section{Limitations}

This study contributes to the body of literature examining why costs for BCS who have BCRL may differ from those who do not have BCRL. Dollar amount estimates were based on the experiences of women in Southeastern Pennsylvania and New Jersey in the year 2015 and may not be generalizable to other regions of the United States; regional variations in insurance coverage may cause cost estimates to vary. This study may underestimate actual costs for the 3-month projected cost estimation. Underreporting was addressed by encouraging participants to supply receipts and medical visit bill summaries in lieu of writing them into the cost diaries themselves; and with monthly text-based, e-mail, and phone messaging reminders to complete the cost diaries, yielding a $>90 \%$ response rate in each month of data collected. This analysis did not have a comprehensive list of contributing factors; nevertheless, these findings suggest a starting point of potential contributing factors on which future studies could focus.

\section{Conclusion}

Our results call for fresh consideration of enduring high outof-pocket costs for breast cancer survivors (BCS) who experience adverse effects after cancer treatment. The study results reinforce the idea that there are significant long-term cost implications for BCS who have BCRL and especially BCS who are socioeconomically challenged. To better reduce cost disparities and provide patient relief from added cost burden, improved and sustained financial coverage (e.g., health insurance and financial assistance) for BCS with BCRL should be considered. Patient-level interventions focused on mitigating or lowering costs for adverse treatment effects should consider both the patient's socioeconomic context and their other healthcare needs. Given the long-term nature of economic challenges for BCS with BCRL, early financial interventions may be warranted to avert long-term economic burden. Upcoming studies should identify social and economic risk profiles of patients who would most benefit from such interventions. 
Funding This work was supported by the National Center for Research Resources and the National Center for Advancing Translational Sciences (NCATS) of the National Institutes of Health through grant 1UL1TR001079 (statistical consultation); the National Cancer Institute grant K01CA184288 (Lorraine T. Dean); the National Institute of Mental Health grant R25MH083620 (Lorraine T. Dean, Yusuf Ransome); the Sidney Kimmel Cancer Center grant P30CA006973 (Lorraine T. Dean, Kala Visvanathan, Yuehan Zhang, Livia Frasso-Jaramillo); Johns Hopkins University Center for AIDS Research grant P30AI094189 (Lorraine T. Dean); the National Institute on Drug Abuse grant T32DA031099 (Shadiya L. Moss), National Institutes of Mental Health K01MH111374 (Yusuf Ransome); and the National Cancer Institute grants R01CA106851 and 1U54CA155850-01 (Kathryn H. Schmitz).

\section{Compliance with ethical standards}

Conflict of interest The authors declare that they have no conflict of interest.

Human rights All procedures performed in studies involving human participants were in accordance with the ethical standards of the institutional and/or national research committee and with the 1964 Helsinki declaration and its later amendments or comparable ethical standards.

Ethical considerations The Institutional Review Board of the University of Pennsylvania approved the study.

Informed consent Written informed consent was obtained from all individual participants included in the study.

Welfare of animals This article does not contain any studies with animals performed by any of the authors.

Open Access This article is distributed under the terms of the Creative Commons Attribution 4.0 International License (http:// creativecommons.org/licenses/by/4.0/), which permits unrestricted use, distribution, and reproduction in any medium, provided you give appropriate credit to the original author(s) and the source, provide a link to the Creative Commons license, and indicate if changes were made.

\section{References}

1. Zafar SY, Peppercorn JM, Schrag D, Taylor DH, Goetzinger AM, Zhong X, et al. The financial toxicity of cancer treatment: a pilot study assessing out-of-pocket expenses and the insured cancer patient's experience. Oncologist. 2013;18(4):381-90.

2. Jagsi R, Pottow JA, Griffith KA, Bradley C, Hamilton AS, Graff J, et al. Long-term financial burden of breast cancer: experiences of a diverse cohort of survivors identified through population-based registries. J Clin Oncol. 2014;32(12):1269-76.

3. Arozullah AM, Calhoun EA, Wolf M, Finley D, Fitzner KA, Heckinger EA, et al. The financial burden of cancer: estimates from a study of insured women with breast cancer. J Support Oncol. 2004;2(3):271-8.

4. Pisu M, Azuero A, Benz R, McNees P, Meneses K. Out-of-pocket costs and burden among rural breast cancer survivors. Cancer Med. 2017;6(3):572-81.

5. Pisu M, Azuero A, Meneses K, Burkhardt J, McNees P. Out of pocket cost comparison between Caucasian and minority breast cancer survivors in the Breast Cancer Education Intervention (BCEI). Breast Cancer Res Treat. 2011;127(2):521-9.
6. Pisu M, Azuero A, McNees P, Burkhardt J, Benz R, Meneses K. The out of pocket cost of breast cancer survivors: a review. J Cancer Surviv. 2010;4:202-9.

7. Oatis W, Nonzee N, Markossian T, Shankaran V, McKoy J, Evens A, et al. Interpreting out-of-pocket expenditures for cancer patients: the importance of considering baseline household income information. J Clin Oncol. 2009;27(15S):6541.

8. Barron JJ, Quimbo R, Nikam PT, Amonkar MM. Assessing the economic burden of breast cancer in a US managed care population. Breast Cancer Res Treat. 2008;109(2):367-77.

9. Vyas A, Madhavan SS, Sambamoorthi U, Pan XL, Regier M, Hazard H, et al. Healthcare utilization and costs during the initial phase of care among elderly women with breast cancer. J Natl Compr Cancer Netw. 2017;15(11):1401-9.

10. Pisu M, Henrikson NB, Banegas MP, Yabroff KR. Costs of cancer along the care continuum: what we can expect based on recent literature. Cancer. 2018;124(21):4181-91.

11. Ekwueme DU, Trogdon JG, Khavjou OA, Guy GP Jr. Productivity costs associated with breast cancer among survivors aged 18-44 years. Am J Prev Med. 2016;50(2):286-94.

12. Bennett CL, Calhoun EA. Evaluating the total costs of chemotherapy-induced febrile neutropenia: results from a pilot study with community oncology cancer patients. Oncologist. 2007;12(4):478-83.

13. Schnur JB, Zivin JG, Mattson DM Jr, Green S, Jandorf LH, Wernicke AG, et al. Acute skin toxicity-related, out-of-pocket expenses in patients with breast cancer treated with external beam radiotherapy. Support Care Cancer. 2012;20(12):3105-13.

14. Barber B. Economic burden of toxicities associated with treating metastatic melanoma in the United States.

15. Irwin DE, Masaquel A, Johnston S, Barnett B. Adverse eventrelated costs for systemic metastatic breast cancer treatment among female Medicaid beneficiaries. J Med Econ. 2016;19(11):1027-33.

16. Hansen RN, Ramsey SD, Lalla D, Masaquel A, Kamath T, Brammer $\mathrm{M}$, et al. Identification and cost of adverse events in metastatic breast cancer in taxane and capecitabine based regimens. Springerplus. 2014;3(1):259.

17. Hurvitz S, Guerin A, Brammer M, Guardino E, Zhou Z-Y, Viau DL, et al. Investigation of adverse-event-related costs for patients with metastatic breast cancer in a real-world setting. Oncologist. 2014;19(9):901-8.

18. Rashid N, Koh HA, Baca HC, Lin KJ, Malecha SE, Masaquel A. Economic burden related to chemotherapy-related adverse events in patients with metastatic breast cancer in an integrated health care system. Breast Cancer: Targets and Therapy. 2016;8:173.

19. Shih Y-CT XY, Cormier JN, Giordano S, Ridner SH, Buchholz TA, et al. Incidence, treatment costs, and complications of lymphedema after breast cancer among women of working age: a 2-year followup study. J Clin Oncol. 2009;27(12):2007-14.

20. Schmitz KH, DiSipio T, Gordon LG, Hayes SC. Adverse breast cancer treatment effects: the economic case for making rehabilitative programs standard of care. Support Care Cancer. 2015;23(6): 1807-17.

21. Dean LT, Schmitz KH, Frick KD, Nicholas LH, Zhang Y, Subramanian S, et al. Consumer credit as a novel marker for economic burden and health after cancer in a diverse population of breast cancer survivors in the USA. J Cancer Surviv. 2018;12(3): 306-15.

22. Boyages J, Xu Y, Kalfa S, Koelmeyer L, Parkinson B, Mackie H, et al. Financial cost of lymphedema borne by women with breast cancer. Psycho-Oncology. 2017;26(6):849-55.

23. Norman SA, Localio Ar PSL, et al. Lymphedema in breast cancer survivors: incidence, degree, time course, treatment, and symptoms. J Clin Oncol. 2009;27(3):390-7.

24. Paskett ED. Symptoms: lymphedema. In: Ganz PA, editor. Improving outcomes for breast cancer survivors. Cham, 
Switzerland: Springer International Publishing AG; 2015. p. 10113.

25. American Cancer Society. Cancer treatment and survivorship facts and figures 2016-2017. Atlanta, GA:2016.

26. Mortimer PS. The pathophysiology of lymphedema. Cancer. 1998;83:2798-802.

27. Petrek JA, Senie RT, Peters M, Rosen PP. Lymphedema in a cohort of breast carcinoma survivors 20 years after diagnosis. Cancer. 2001;92:1368-77.

28. Bernas M. International Society of Lymphology Executive Committee, the diagnosis and treatment of peripheral lymphedema-draft revision of the 1995 consensus document of the international society of lymphology executive committee for discussion at the September 3-7, XVIIIth international congress of lymphology in Genoa, Italy. Lymphology. 2001;34(2):84-91.

29. Dean LT, Kumar A, Kim T, Herling M, Brown JC, Zhang Z, et al. Race or resource? BMI, race, and other social factors as risk factors for interlimb differences among overweight breast cancer survivors with lymphedema. J Obes. 2016;2016(8241710).

30. Dean LT, Moss SL, Ransome Y, Frasso-Jaramillo L, Zhang Y, Visvanathan K, et al. "It still affects our economic situation" Long-term economic burden of breast cancer and lymphedema. $\mathrm{J}$ Support Care Cancer. 2018;27:1-12.

31. Schmitz KH, Ahmed RL, Troxel AB, Cheville A, Lewis-Grant L, Smith R, et al. Weight lifting for women at risk for breast cancerrelated lymphedema: a randomized trial. Jama. 2010;304(24): 2699-705.

32. Schmitz KH, Troxel AB, Cheville A, Grant LL, Bryan CJ, Gross $\mathrm{CR}$, et al. Physical Activity and Lymphedema (the PAL trial): assessing the safety of progressive strength training in breast cancer survivors. Contemp Clin Trials. 2009;30(3):233-45.

33. Winkels RM, Sturgeon KM, Kallan MJ, Dean LT, Zhang Z, Evangelisti M, et al. The Women In Steady Exercise Research (WISER) Survivor trial: the innovative transdisciplinary design of a randomized controlled trial of exercise and weight-loss interventions among breast cancer survivors with lymphedema. Contemp Clin Trials. 2017;61:63-72.

34. Schmitz KH, Troxel AB, Dean LT, De Michele A, Brown JC, Sturgeon K, et al. Effect of home-based exercise and weight loss programs on breast cancer-related lymphedema outcomes among overweight breast cancer survivors: The WISER Survivor randomized clinical trial. JAMA Oncol. 2019; [in press].

35. Patterson RE, Colditz GA, Hu FB, Schmitz KH, Ahima RS, Brownson RC, et al. The 2011-2016 Transdisciplinary Research on Energetics and Cancer (TREC) initiative: rationale and design. Cancer Causes Control. 2013;24(4):695-704.

36. Patton MQ. Qualitative evaluation and research methods. Thousand Oaks: SAGE Publications, inc; 1990.

37. Berkman L, Macintyre S. The measurement of social class in health studies: old measures and new formulations. IARC Sci Publ. 1997;138:51-64.

38. Goossens M, Rutten-van Molken M, Vlaeyen J, van der Linden S. The cost diary: a method to measure direct and indirect costs in cost-effectiveness research. J Clin Epidemiol. 2000;53(7):688-95.
39. Van den Berg B, Brouwer W, van Exel J, Koopmanschap M, van den Bos GA, Rutten F. Economic valuation of informal care: lessons from the application of the opportunity costs and proxy good methods. Soc Sci Med. 2006;62(4):835-45.

40. US Bureau of Labor Statistics. National occupational employment and wage estimates, United States. http://www.bls.gov/oes/current/ oes_nat.htm.

41. Grosse SD, Krueger KV, Mvundura M. Economic productivity by age and sex: 2007 Estimates for the United States. Med Care 2009: S94-S103.

42. US Bureau of Labor Statistics. Consumer Price Index. http://www. bls.gov/cpi/data.htm.

43. Oberst K, Bradley CJ, Schenk M. Breast and prostate cancer patient's reliability of treatment reporting. J Registry Manag. 2008;36(1):12-5.

44. Brown ML, Yabroff KR. Chapter 12: Economic impact of cancer in the United States. In: Fraumeni J, Schottenfeld D, editors. Cancer epidemiology and prevention. Oxford: Oxford University Press; 2006. p. 202-16.

45. Creswell JW, Plano Clark VL, Gutmann ML, Hanson WE. Advanced mixed methods research designs. In: Handbook of mixed methods in social and behavioral research, vol. 209; 2003. p. 240.

46. Ivankova NV, Creswell JW, Stick SL. Using mixed-methods sequential explanatory design: from theory to practice. Field Methods. 2006;18(1):3-20.

47. Zafar SY, Newcomer LN, Jusfin McCarthy J, Nasso SF, Saltz LB. How should we intervene on the financial toxicity of cancer care? One shot, four perspectives. ASCO educational book. 2017;37:359.

48. Zafar SY. Financial toxicity of cancer care: it's time to intervene. J Natl Cancer Inst. 2016;108(5):djv370.

49. National Research Council. From cancer patient to cancer survivor: lost in transition. Washington, D.C: National Academies Press; 2005.

50. Dean LT, Moss SL, Rollinson SI, Frasso-Jaramillo L, Paxton RJ, Owczarak JT. Patient recommendations for reducing long-lasting economic burden after breast cancer. Cancer. 2019;125(11):1929 40.

51. Weiss R. Cost of a lymphedema treatment mandate-10 years of experience in the Commonwealth of Virginia. Heal Econ Rev. 2016;6(1):42.

52. Lymphedema Treatment Act: background \& history. http:// lymphedematreatmentact.org/about-the-bill/backgroundinformation/. Accessed 3 Oct 2017.

53. Cliff BQ, Rozier M, Fendrick AM. Health insurance benefits should be equitable, not necessarily equal. health affairs blog: Health Equity2017.

Publisher's note Springer Nature remains neutral with regard to jurisdictional claims in published maps and institutional affiliations. 